\title{
Nanoplasmonic biosensors: current perspectives
}

\author{
This article was published in the following Dove Press journal: \\ Nanobiosensors in Disease Diagnosis \\ 10 September 2015 \\ Number of times this article has been viewed
}

\author{
Gauri M Shukla \\ Soumyo Mukherji \\ Department of Bioscience and \\ Bioengineering, IIT Bombay, Mumbai, \\ Maharashtra, India
}

\begin{abstract}
Recent advances in nanotechnology and nanofabrication have helped develop a wide variety of nanostructured platforms for use as nanoplasmonic biosensors. These can either be in solution phase or be confined on a substrate in the form of metallic nanofilms or periodic arrays. Plasmonic properties of these nanostructures depend on the size, shape, position, orientation, etc, and can be altered by interaction between probe and target species on the metal surfaces. This property of nanostructures has been exploited in refractometric nanoplasmonic biosensors, surface-enhanced Raman spectroscopy-based biosensors, plasmon-enhanced fluorescence biosensors, etc. These nanoplasmonic biosensors are employed in diverse areas such as clinical diagnosis, biosecurity, food, and environmental monitoring. Among these, clinical diagnosis has attracted the most research and commercial interest. Nanoplasmonic biosensors can detect disease biomarkers using highly specific and selective biological recognition elements on the nanostructured surfaces. Many excellent reviews exist in this area that trace the developments over the past 3 decades. This review focuses on some of the more recent studies on the detection of various disease biomarkers through nanoplasmonic biosensors. In the process, we have described fabrication techniques and biofunctionalization of such biosensors.
\end{abstract}

Keywords: nanostructures, localized surface plasmon resonance (LSPR), surface-enhanced Raman spectroscopy (SERS)

\section{Introduction}

Over the past few decades, research in the field of biosensors has been moving toward the development of point-of-care devices that ensure high sensitivity, fast response, and real-time analysis. Among the different categories of biosensors, optical biosensors have been extensively explored, as they are capable of rapid, reproducible, highly sensitive, and label-free analysis. Optical biosensors based on nanoplasmonics offer remarkable potential for incorporation in lab-on-a-chip devices and multiplexed measurements.

Plasmonics is a field that studies generation, manipulation, and transfer of surface plasmons (SPs). ${ }^{1}$ SPs are excited at the interface of noble metals and dielectrics having oppositely signed real part of the dielectric constant, and they can be propagating or localized in nature. Propagating SPs can be excited on thin metal films. Under certain conditions of excitation, resonance between the incident photons and SPs is seen. This is known as surface plasmon resonance (SPR), which is utilized in SPRbased biosensors. SPR is well established as a label-free biosensing platform, but it is difficult to employ them in point-of-care devices. In this regard, nanoplasmonics, ie, the fabrication of nanostructures and characterization of their plasmonic properties, has a significant role to play. Localized surface plasmons (LSPs) can be excited on
Correspondence: Soumyo Mukherj Department of Biosciences and Bioengineering, IIT Bombay, Powai, Mumbai 400 076, India

Tel +9l 2225767767

Fax +9I 2225723480

Email mukherji@iitb.ac.in 
subwavelength-sized metal nanostructures. The frequency of localized surface plasmon resonance (LSPR) is determined by the complex dielectric function of a metal and dielectric constant of the surrounding medium. Localized field confinement around nanostructures improves the sensitivity of these structures toward physicochemical changes in the immediate (nanoscale) environment. This property of nanostructures is exploited in nanoplasmonic biosensors. LSPR can be excited with direct electromagnetic (EM) illumination, indicating ease of miniaturization. The nanostructures can be further coupled with microfluidic structures and/or embedded electronics to develop integrated systems.

The most commonly used plasmonic materials are gold and silver. ${ }^{2}$ Silver nanoparticles display sharper and more intense LSPR than gold nanoparticles (GNPs), but are prone to oxidation. GNPs are widely preferred due to their higher chemical stability and capability of biofunctionalization using thiol chemistry-assisted self-assembled monolayers. ${ }^{3}$ Strategies for synthesis of different types of gold colloids have been summarized earlier by our group. ${ }^{4}$ More recently, aluminum and copper have been explored as potential nanoplasmonic material. $^{5}$

Plasmonic nanostructures can serve as refractometric sensing platforms, surface-enhanced Raman scattering (SERS) platforms, or even surface-enhanced luminescence platforms. In refractometric nanoplasmonic biosensors, refractive index change in the vicinity of a metal structure due to biomolecules conjugation is sensed as LSPR wavelength shift or change in absorbance. SPs excited on nanostructures enhance fluorescence or Raman intensity of labels, which are exploited in plasmon-enhanced fluorescence and SERS-based biosensors respectively. ${ }^{6}$ The enhancement is governed not only by the size, shape, position, and orientation of the metal nanostructures, but also by the interactions among the probe and target species on the metal surface and the microenvironment. ${ }^{7}$ Researchers have also studied the formation of hot spots, ie, small regions of highly enhanced EM field, to obtain high SERS intensity. ${ }^{8,9}$

Nanostructures either exist in solution phase or are confined on a substrate in the form of a nanofilm or a periodic array. Historically, a large number of studies exist on nanoplasmonic biosensors based on solution phase nanoparticles, where aggregation of nanoparticles is used for the determination of biomolecular interactions. With the advent of newer wet chemistry methods, ${ }^{10}$ it is possible to synthesize nanoparticles having shapes other than nanospheres, such as nanorods, nanotriangles, nanocubes, nanorice, nanostars, nanocages, and core-shell nanoparticles. Frequently, these particles have low stability in solution, giving rise to low shelf life and thus limited use in biosensing. ${ }^{5}$ The nature of solvent, its $\mathrm{pH}$, presence of stabilizers, and surfactants can also influence their performance as biosensors. Conversely, surface-confined nanostructures offer high stability, possibility of integration, and assay system miniaturization.

Confinement of colloidal nanoparticles on substrates is achieved via surface modification. When nanoparticles are dispersed on substrates, the position and orientation of nanoparticles, and uniformity of surface coverage present significant challenges. Alternately, nanostructures can be grown directly on substrates using top-down, bottom-up, combination techniques and template-assisted fabrication. Top-down techniques are based on advanced lithographic techniques like electron beam lithography (EBL), or focused ion beam. The fabricated nanostructures display distinct size, shape, and spatial distribution. However, these techniques are slow and expensive, and generate small patterned region. The low-cost alternative to these is nanosphere lithography (NSL) or hole-mask colloidal lithography, which involves sacrificial masks to fabricate ordered arrays of nanostructures. Template-assisted fabrication frequently utilizes hard templates of anodized aluminum oxide (AAO). ${ }^{11}$ All of these nanofabrication techniques have been extensively reviewed by many groups. ${ }^{12-19}$

Another important aspect of nanoplasmonic biosensors is the functionalization of the nanostructures, which is essential for any biochemical sensor, with recognition/receptor/ capture molecules, such as proteins, ligands, nucleic acids, etc. Researchers have employed a wide variety of techniques to develop stable functional groups on the nanostructures, which do not lose their functionality/reactivity due to surface confinement. In this review, we focus mainly on the nanoplasmonic biosensors employed in disease diagnostics, from the point of view of nanostructure synthesis/fabrication and biofunctionalization. We have also confined our review to studies published during the last decade.

\section{Disease diagnosis}

Detection of biomarkers is a key factor for disease diagnosis as they are produced by diseased organ or by the body in response to disease. Developments in genomics, proteomics, and molecular pathology have generated many biomarkers with potential clinical value. They can be used for screening and risk assessment. Biomarkers can determine staging, grading, and selection of initial treatment. During treatment, they can be used to monitor therapy, select additional therapy, or monitor recurrent diseases. As in other sensor platforms, 
plasmonic nanoparticles or structures may be converted into biosensors by employing highly specific and selective biological recognition elements on their surface. The following sections discuss the various types of sensors developed of late for the most prevalent groups of diseases.

\section{Cancer diagnosis}

Cancer biomarkers are generally proteins overexpressed in blood or serum or at the surface of cancer cells. ${ }^{20}$ Early detection of cancer is quite difficult as the concentration of these biomarkers is rather low in the initial stages of cancer. As a result, there is a tremendous interest in the scientific community to address this challenge, and various nanostructures have been proposed for the detection of cancer biomarkers (Table 1).

Many research groups have employed GNPs for the detection of various cancer biomarkers. A colloidal GNP-based nanoplasmonic aptamer sensor (aptasensor) (Figure 1) was developed for the detection of vascular endothelial growth factor-165 (VEGF 165), biomarker of cancer angiogenesis. ${ }^{21}$ Aptamer developed toward VEGF 165, and labeled with Cy3B, was electrostatically bound to a positively charged poly-L-lysine (PLL)-coated GNP surface. This conjugate exhibited surface-enhanced fluorescence (SEF) because of the metal interaction increasing the radiative fluorescent decay rate of Cy3B. Incubation with VEGF 165 leads to detachment

Table I Nanoplasmonic biosensors for cancer diagnosis

\begin{tabular}{|c|c|c|c|c|c|c|}
\hline $\begin{array}{l}\text { Nanostructure } \\
\text { type }\end{array}$ & Probe moieties & Analytes & $\begin{array}{l}\text { Limit of } \\
\text { detection }\end{array}$ & $\begin{array}{l}\text { Substrate } \\
\text { type }\end{array}$ & $\begin{array}{l}\text { Detection } \\
\text { mechanism }\end{array}$ & References \\
\hline GNP & VEGF I 65 aptamer & VEGF I65 & - & Colloidal & SEF & Cho et $\mathrm{al}^{2 \mathrm{I}}$ \\
\hline $\begin{array}{l}\text { GNP/PSA-ACT/ } \\
\text { magnetic microbeads }\end{array}$ & PSA-ACT mAb & PSA-ACT & $\mathrm{I} \mathrm{pg} / \mathrm{mL}$ & Colloidal & LSPR & Cao et $\mathrm{al}^{22}$ \\
\hline Spherical GNP & PSA-ACT mAb & PSA-ACT & $0.1 \mathrm{pg} / \mathrm{mL}$ & Glass & $\begin{array}{l}\text { Rayleigh light } \\
\text { scattering }\end{array}$ & Hwang et al ${ }^{23}$ \\
\hline GNPs & Antihuman AFP - MBA - GNPs & AFP & 100 pg/mL & Glass & SERS & Wang et $\mathrm{al}^{24}$ \\
\hline GNS & $\begin{array}{l}\text { Capture antibody/target AFP/ } \\
\text { fluorophores labeled secondary } \\
\text { antibody }\end{array}$ & AFP & $0.1 \mathrm{ng} / \mathrm{mL}$ & Optical fiber & LSPR & Chang et $\mathrm{al}^{25}$ \\
\hline Spherical GNP & $\begin{array}{l}\text { Capture antibody PSA } \\
\text { (PSA I0), tracer antibody } \\
\text { PSA (PSA 66) }\end{array}$ & PSA & I pg/mL & Optical fiber & LSPR & Jeong et $\mathrm{al}^{26}$ \\
\hline GNPs & $\begin{array}{l}\text { First antibody/AFP/GNP } \\
\text { conjugated secondary } \\
\text { antibody }\end{array}$ & AFP & $\begin{array}{l}0.2 \mathrm{ng} / \mathrm{mL} \text { in PBS } \\
\text { and } 2 \mathrm{ng} / \mathrm{mL} \text { in } \\
\text { bovine serum }\end{array}$ & $\begin{array}{l}\text { Optical } \\
\text { microfiber }\end{array}$ & LSPR & Li et $\mathrm{al}^{27}$ \\
\hline Gold-on-gold films & $\begin{array}{l}\text { MaCEA, polyclonal rabbit } \\
\text { anti-CEA IgG, goat anti-rabbit } \\
\text { IgG conjugated to IR } 800\end{array}$ & CEA & $5 \mathrm{fM}$ & Glass & SEF & $\begin{array}{l}\text { Tabakman } \\
\text { et } \mathrm{al}^{28}\end{array}$ \\
\hline Gold film island & Anti-AFP antibody & AFP & $25 \mathrm{ng} / \mathrm{mL}$ & Quartz slides & LSPR & Geng et $\mathrm{al}^{29}$ \\
\hline $\begin{array}{l}\text { Au triangle } \\
\text { nanoarray }\end{array}$ & $\begin{array}{l}\text { Gold nanostar conjugated } \\
\text { with Raman label malachite } \\
\text { green and detection antibody, } \\
\text { capture antibody }\end{array}$ & VEGF & - & Glass & SERS & Li et $\mathrm{al}^{30}$ \\
\hline $\begin{array}{l}\text { Elliptical Au nanodisk } \\
\text { arrays }\end{array}$ & $\begin{array}{l}\text { Anti-PSA antibodies, alkaline } \\
\text { phosphatase labeled secondary } \\
\text { antibody }\end{array}$ & PSA & - & Glass & LSPR & Lee et $\mathrm{al}^{31}$ \\
\hline Gold nanodisk array & PSA mAb & f-PSA & $100 \mathrm{fg} / \mathrm{mL}$ & Optical fiber & LSPR & Sanders et $\mathrm{al}^{32}$ \\
\hline GNR & PSA mAb & PSA-ACT & $\mathrm{I} a \mathrm{M}$ & Glass & LSPR & Truong et $\mathrm{al}^{33}$ \\
\hline GNR & $\begin{array}{l}\text { Anti-HER2 primary antibody, } \\
\text { anti-rabbit lgGs secondary } \\
\text { antibody }\end{array}$ & HER2 & - & Glass & SERS & Park et $\mathrm{al}^{34}$ \\
\hline $\mathrm{Au@Ag} \mathrm{NRs}$ & Rabbit anti-p53 and p2I & p53 and p2I & I pg/mL & Glass & SERS & Wu et $\mathrm{al}^{38}$ \\
\hline Silver nanochip & Anti-HE4 antibody & HE4 & $4 \mathrm{pM}$ & Glass & LSPR & Yuan et $\mathrm{al}^{4 !}$ \\
\hline $\begin{array}{l}\text { Triangular-shaped } \\
\text { silver nanoparticle }\end{array}$ & DNA probe & p53 & - & Glass & LSPR & Duan et $\mathrm{al}^{42}$ \\
\hline
\end{tabular}

Abbreviations: GNP, gold nanoparticle; VEGF, vascular endothelial growth factor; SEF, surface-enhanced fluorescence; PSA, prostate-specific antigen; PSA-ACT, PSA complexed to R-I-antichymotrypsin; PSA-ACT mAb, PSA-ACT monoclonal antibody; LSPR, localized surface plasmon resonance; MBA, mercaptobenzoic acid; AFP, alpha-fetoprotein; SERS, surface-enhanced Raman scattering; MaCEA, monoclonal mouse anti-CEA IgG; CEA, carcinoembryonic antigen; GNR, gold nanorods; f-PSA, free PSA; HER2, human epidermal growth factor receptor 2; Au@Ag NRs, Gold@silver core-shell nanorods; HE4, human epididymis secretory protein 4; GNS, gold nanosphere; IgG, immunoglobulin G. 


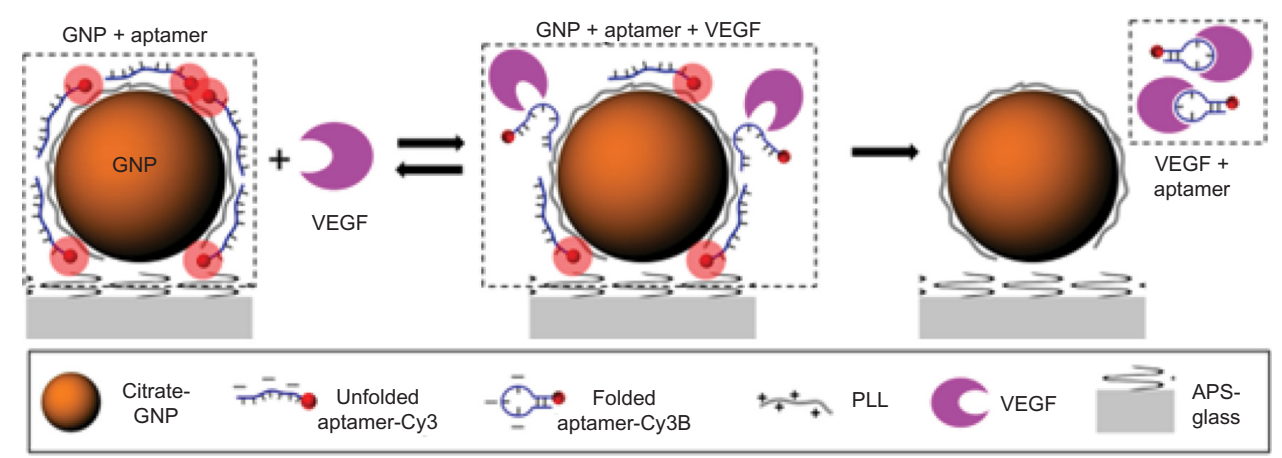

Figure I Schematics of the aptasensor illustrating detection mechanism of VEGF I 65.

Notes: Reprinted with permission from Cho H, Yeh EC, Sinha R, Laurence TA, Bearinger JP, Lee LP. Single-step nanoplasmonic VEGF 165 aptasensor for early cancer diagnosis. ACS Nano. 20I2;6(9):7607-76I4. ${ }^{21}$ Copyright (C) 20I2, American Chemical Society.

Abbreviations: GNP, gold nanoparticles; VEGF, vascular endothelial growth factor; PLL, poly-L-lysine; APS, (3-Aminopropyl) triethoxysilane.

of the aptamer from the GNP surface, causing reduced SEF effect from Cy3B. This assay showed a linear detection from $25 \mathrm{pg} / \mathrm{mL}$ to $25 \mu \mathrm{g} / \mathrm{mL}$. Cao et al ${ }^{22}$ demonstrated the detection of prostate-specific antigen (PSA) protein biomarker utilizing homogeneous growth of Au nanocrystals in solution phase. The two prime forms of PSA in human serum are free PSA (f-PSA) and PSA complexed to R-1-antichymotrypsin (PSA-ACT). ${ }^{20} \mathrm{~A}$ sandwich-immunoassay of gold immunoprobe/PSA-ACT/magnetic microbead probes (MMP) was developed for detection of PSA-ACT. Gold immunoprobe was obtained by immobilizing PSA-ACT monoclonal antibody (PSA-ACT mAb) on gold seeds, whereas MMP immunoprobe was obtained by immobilization of goat PSA polyclonal antibody (PSA pAb). After immunoreaction, gold immunoprobe/PSA-ACT/MMP immunoprobe complexes were separated by magnetic separation. Following this, a growth solution was introduced for gold deposition onto the gold seeds in the complex. Monitoring the changes in absorbance wavelength due to the growth of GNPs allowed for sensitivity as low as $1 \mathrm{pg} / \mathrm{mL}$.

Immobilization of GNPs on glass substrate was achieved by drop coating. ${ }^{23}$ The plasmonic response of single GNP of varied sizes was investigated for PSA recognition. PSA-ACT complex was detected by immobilizing PSA $m A b$ on spherical GNP. Rayleigh spectra for scattered light were collected from individual GNPs using a dark-field microspectroscopy system. The total linear dynamic range was found to be in the concentration range of $10^{-4}$ to $10 \mathrm{ng} / \mathrm{mL}$, and the detection limit was $0.1 \mathrm{pg} / \mathrm{mL}$. In another study, Wang et $\mathrm{a}^{24}$ have modified GNP surfaces with mercaptobenzoic acid (MBA) and antihuman AFP (alpha-fetoprotein). In parallel, glass slides were modified with poly(diallyldimethylammonium chloride) for GNP binding, and then covered with different concentrations of human AFP (a marker for hepatocellular carcinomas).
When the slides were immersed in antihuman AFP-MBAGNP solution, the antibody-antigen binding affected the intensity of SERS spectra, which showed a distinct dependence on the AFP concentration. The detection limits for AFP were reached as low as $100 \mathrm{pg} / \mathrm{mL}$.

Further, fiber-optic biosensors based on LSP coupled fluorescence were developed for AFP detection..$^{25}$ This particular sensor scheme utilized a sandwich assay format through capture antibody/target AFP/ fluorophores labeled secondary antibody immobilized on gold nanosphere (GNS). The detection limit achieved was $0.1 \mathrm{ng} / \mathrm{mL}(1.4 \mathrm{pM})$ in phosphate-buffered saline (PBS) solution. Recently, Jeong et $\mathrm{al}^{26}$ fabricated optical fiber-LSPR sensors using spherical GNPs. Synthesized colloidal GNPs were immobilized on the end face of optical fibers by self-assembly. The sensor was tested for PSA detection using capture antibody PSA (PSA 10), tracer antibody PSA (PSA 66), and antigen PSA available in commercial ELISA kits. The limit of detection (LOD) was $1 \mathrm{pg} / \mathrm{mL}$. Compared with traditional fiber optic-based biosensors, Li et $\mathrm{al}^{27}$ demonstrated an optical microfiber (OMF) biosensor using GNPs as amplification labels for AFP detection. In this sandwiched assay format that used gold-tagged secondary antibody, the capture antibody was immobilized on OMF (diameter $1 \mu \mathrm{m}$ ), and the secondary antibody was functionalized with GNPs (40 nm). The LOD for AFP was $0.2 \mathrm{ng} / \mathrm{mL}$ in PBS and $2 \mathrm{ng} / \mathrm{mL}$ in bovine serum.

Apart from immobilization of colloidal GNPs on substrate, GNPs were grown directly on the substrate in the form of a film or nanoarray. Gold-on-gold films were fabricated on glass slides by $\mathrm{Au}$ seeding and subsequent $\mathrm{Au}$ growth. Carcinoembryonic antigen (CEA, a biomarker of gastrointestinal tract cancer) cancer biomarker detection was demonstrated on such films. ${ }^{28}$ The sensor surface was immobilized with monoclonal mouse anti-CEA IgG (MaCEA). The binding 
of CEA with MaCEA was detected by polyclonal rabbit antiCEA IgG and successive labeling by goat anti-rabbit IgG conjugated with IR800. Fluorescence enhancement was seen for CEA concentration ranging from $1 \mathrm{fM}$ to $100 \mathrm{pM}$ with $\sim 5 \mathrm{fM}$ detection limit. In a recent study, Au film islands were prepared on quartz slides by e-beam evaporation followed by thermal annealing. ${ }^{29}$ This sensor platform was integrated with microfluidics for AFP detection. It was able to detect $25 \mathrm{ng}$ / $\mathrm{mL}$ concentration of the liver cancer marker.

Different lithography techniques were employed to fabricate Au nanoarrays. Au triangular nanoarray chip-based SERS immunosensor was constructed for VEGF detection. ${ }^{30}$ The Au triangle nanoarray was fabricated by NSL over which capture antibody was immobilized (Figure 2). Gold nanostars were conjugated with Raman label malachite green isothiocyanate (MGITC) followed by $\mathrm{SiO}_{2}$ coating. Detection antibody was immobilized on these nanoparticles. VEGF concentration measured by this SERS immunosensor showed a high degree of correspondence with results obtained using enzyme-linked immunosorbent assay (ELISA). Lee et $\mathrm{al}^{31}$ developed elliptical Au nanodisk arrays as sensing substrate. Long-range ordered nanodisk arrays were fabricated using serial processes of nanoimprint lithography, tilted evaporation, oxygen plasma etching, metal deposition and lift-off. The nanodisk surface was modified with anti-PSA antibodies for PSA detection. Alkaline phosphatase labeled secondary antibody was then conjugated to PSA. The reduction of the 5-bromo-4-chloro3-indolyl phosphate $p$-toluidine/nitro blue tetrazolium (BCIP/ NBT) by alkaline phosphatase produced insoluble precipitate on the nanodisk surfaces that resulted in significant change in the LSPR signal. The detection limit of femtomolar was attained using this sensor. Nanodisks were also used by Sanders et al, ${ }^{32}$ who developed LSPR-coupled optical fiber probes for f-PSA detection. Gold nanodisk arrays were fabricated directly on the end facet of a fiber using EBL and metal liftoff process. Mouse antihuman PSA mAb was immobilized on these gold nanodisks. The LOD of f-PSA was $100 \mathrm{fg} / \mathrm{mL}$.

Besides spherical GNP, gold nanorods (GNRs) are widely exploited in biosensing applications. In addition to their immobilization on the substrate, core-shell nanorods were established for sensing applications. GNRs modified with oligo(ethylene glycol) thiols (OEGs) were demonstrated for PSA-ACT complex detection. ${ }^{33}$ GNRs were first anchored onto a glass substrate followed by immobilization of PSA $\mathrm{mAb}$ onto GNR. The lowest concentration of PSA detected was 1 aM. In another study, Park et $\mathrm{al}^{34}$ demonstrated potential use of antibody-conjugated GNR for imaging of human epidermal growth factor receptor 2 (HER2) using the SERS method. HER2 expressed on the surface membrane of immortalized human breast adenocarcinoma MCF7 cells is a prominent molecular marker of breast cancer. Raman reporter molecules, mercaptopyridine were attached to the surface of GNRs followed by secondary antibodies, antirabbit IgGs immobilization. HER2 markers expressed on the cell surface were treated with anti-HER2 primary antibodies. The functionalized nanoprobes, conjugated with secondary antibodies, were then attached by antibody-antibody interactions. Later a GNR aggregation-based biosensor was developed by immobilizing AFP monoclonal antibody for AFP detection from PBS. ${ }^{35}$ LOD and limit of quantification (LOQ) of the AFP detection of this method using GNRs aggregation were found to be 0.04 and $0.14 \mathrm{nM}$, respectively. Recently, bioplasmonic paper comprised of GNRs was demonstrated as a LSPR biosensor for aquaporin-1 (AQP1) detection. ${ }^{36} \mathrm{AQP} 1$ is an excellent biomarker for the noninvasive and early detection of renal cancer. Bioplasmonic paper comprised of GNRs functionalized with antiAQP1 adsorbed on a filter paper. The detection of kidney

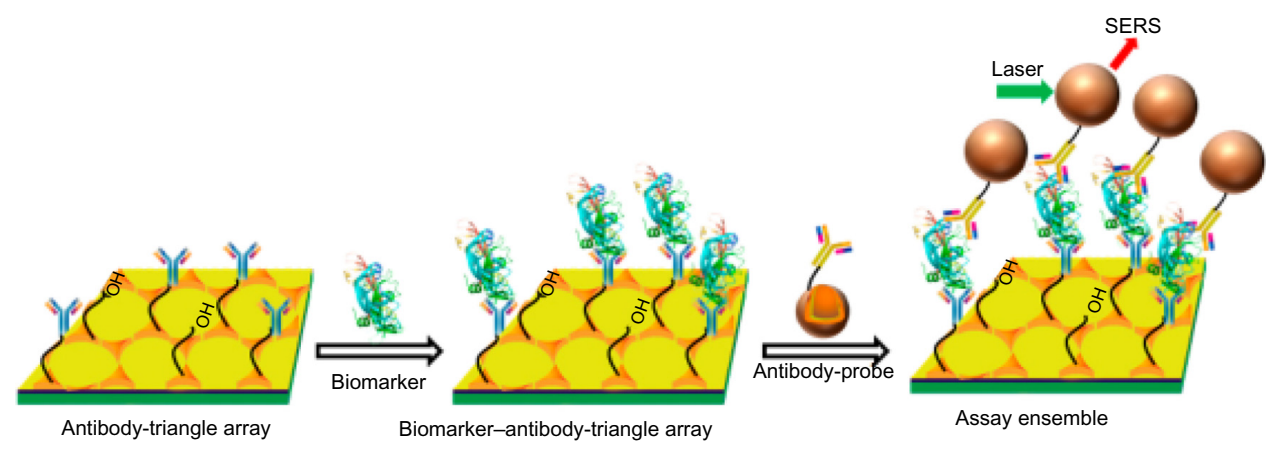

Figure 2 Scheme of VEGF biomarker detection using SERS immunosensor.

Notes: Reprinted with permission from Li M, Cushing SK, Zhang J, et al. Three-dimensional hierarchical plasmonic nano-architecture enhanced surface-enhanced Raman scattering immunosensor for cancer biomarker detection in blood plasma. ACS Nano. 2013;7(6):4967-4976. ${ }^{30}$ Copyright (C) 2013, American Chemical Society. Abbreviations: VEGF, vascular endothelial growth factor; SERS, surface-enhanced Raman spectroscopy. 
cancer biomarkers in artificial urine down to $10 \mathrm{ng} / \mathrm{mL}$ was seen. Silver-coated gold nanorods (AuNR/Ag) were demonstrated for highly specific detection of single breast cancer cells in unprocessed human blood using SERS (Figure 3). ${ }^{37}$ AuNR/Ag were divided into four groups, each being conjugated with a unique organic Raman molecule 4MBA, $p$-aminothiophenol [PATP], $p$-nitrothiophenol [PNTP], and 4-(methylsulfanyl) thiophenol [4MSTP], having different SERS spectra, and a different antibody specific to four breast cancer markers: antiepithelial cells adhesion molecules (antiEpCAM), anti-CD44, anti-Keratin18, and anti-insulin-like growth factor antigen (anti-IGF-I receptor $\beta$ ). Using the antibody combination, high specificity was observed for targeting breast cancer cells. More recently, Wu et al ${ }^{38}$ demonstrated the simultaneous detection of p53 and p21 using the SERS technique. p53 overexpression in the absence of p21 expression (ie, p53 positive/p21 negative) could be a useful marker in the diagnoses of epithelial ovarian cancer, colorectal cancer, and hepatocellular carcinoma. ${ }^{38}$ Gold@silver core-shell nanorods (Au@Ag NRs) were conjugated with two different Raman reporters 4MBA and 5,5-dithiobis(2-nitrobenzoic acid) (DTNB). p53 detection was achieved by 4MBA-labeled Au@Ag nanorods with rabbit anti-p53 conjugation, while p21 sensing was accomplished by DTNB-labeled Au@Ag NRs with rabbit anti-p21 conjugation. The detection limit down to $1 \mathrm{pg} / \mathrm{mL}$ was attained. Recently, another group fabricated nanorod arrays (of $200 \mathrm{~nm}$ length and $50 \mathrm{~nm}$ width) with $300 \times 500 \mathrm{~nm}$ period by EBL. ${ }^{39}$ Detection of single nucleotide polymorphism in codon 12 of the K-ras gene, frequently occurring in early stages of colon cancer, was demonstrated on this sensor platform. Sensitivity down to $10 \mathrm{nM}$ in the presence of 100 -fold higher concentration of the homozygous genotypes was obtained.

An interesting structure in the form of a gold mushroom array has been fabricated in order to detect cytochrome $\mathrm{c}$ and AFP ${ }^{40}$ A periodic array of photoresist pillars (480 $\mathrm{nm}$ in height) in a square lattice was fabricated using double twobeam interference lithography. It was subsequently covered with gold by thermal evaporation. Authors demonstrated detection of the analytes with LOD down to $200 \mathrm{pM}$ and $15 \mathrm{ng} / \mathrm{mL}$, respectively.

Analogous to GNPs, lithography techniques were utilized to produce silver nanochips. Using the NSL technique, Yuan et al fabricated silver nanochips for the detection of human epididymis secretory protein 4 (HE4) biomarker, ${ }^{41}$ which may be used for early detection of ovarian cancer. Anti-HE4 antibodies were immobilized onto a nanochip surface using an amine coupling method. The shift in the extinction maximum of the LSPR spectrum was shown to be linear for HE4 concentration ranging from 10 to $10,000 \mathrm{pM}$. The detection limit of $4 \mathrm{pM}$ was observed. Similarly, Duan et $\mathrm{al}^{42}$ developed a LSPR biosensor chip for detecting p53 mutation. Triangular-shaped silver nanoparticles were fabricated on glass substrate by the NSL technique, on which DNA probes were covalently coupled. The synthetic oligonucleotides and polymerase chain reaction products amplified from patient blood samples were detected reasonably well using this sensor. The shift in LSPR extinction peak due to the binding of two target DNAs, wild-type and mutant p53, was significant, suggesting that the sensor could discriminate against single-base mutations.

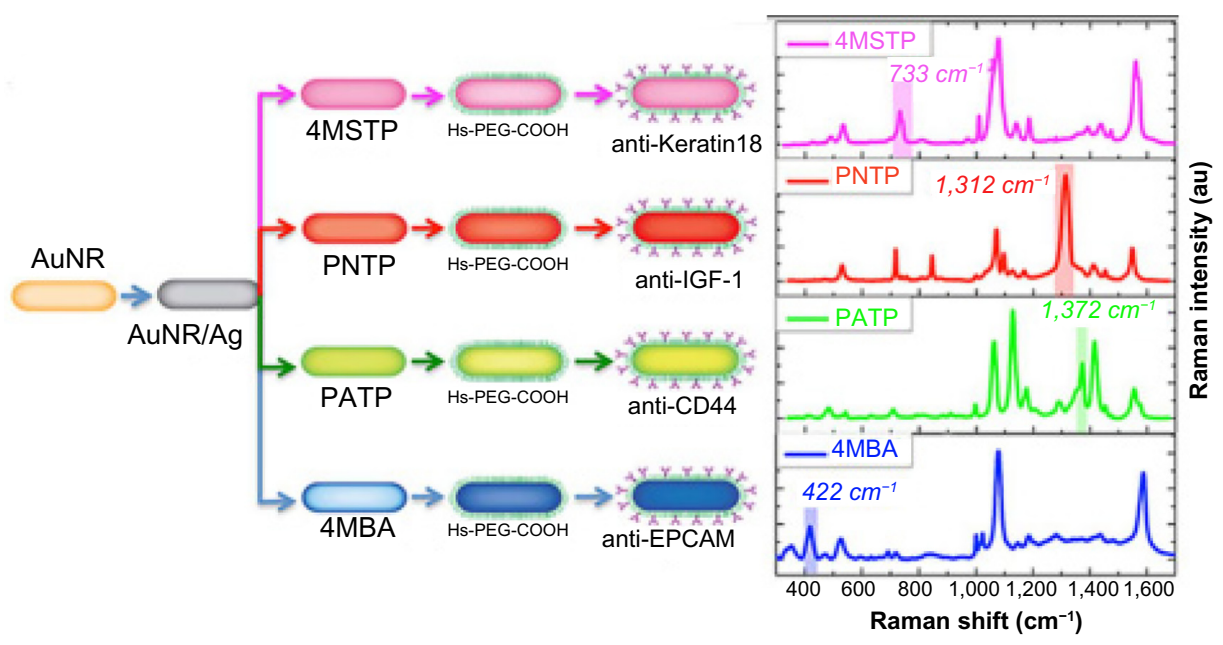

Figure 3 Schematic showing detection of breast cancer markers using silver-coated gold nanorods conjugated with four families of SERS nanoagents.

Note: Reproduced from Nima ZA, Mahmood M, Xu Y, et al. Circulating tumor cell identification by functionalized silver-gold nanorods with multicolor, super-enhanced SERS and photothermal resonances. Sci Rep. 20I4;4:4752. ${ }^{37}$

Abbreviations: PATP, p-aminothiophenol; PNTP, p-nitrothiophenol; MSTP, methylsulfanyl) thiophenol; MBA, mercaptobenzoic acid; anti-EPCAM, anti-epithelial cells adhesion molecules; PEG, polyethylene glycol; AuNR/Ag, silver-coated gold nanorods; AuNR, gold nanorod; AuNR, gold nanorod; SERS, surface-enhanced Raman scattering. 


\section{Viral diseases/pathogenic diseases}

Biomarkers for various pathogenic diseases such as avian influenza (AI), hepatitis B, dengue, and HIV are commonly known. SERS and LSPR-based sensing platforms for biomarkers for different pathogenic diseases are summarized in Table 2, and a brief description of some of these is presented in this section.

GNPs in solution phase were utilized for the development of sandwiched assay for anti-West Nile Virus (WNV) envelope (E) immunoglobulin detection. ${ }^{43}$ GNPs coated with the E protein of WNV served as a SERS-active substrate and MGconjugated protein $\mathrm{A} / \mathrm{G}(\mathrm{MG}-\mathrm{pA} / \mathrm{G})$ as a bifunctional Raman tag/antibody binding reporter. The detection sensitivity of $50 \mathrm{pg} / \mathrm{mL}$ was observed for anti-WNV E immunoglobulin. To capture HIV on the biosensing surface, Inci et al first modified polystyrene surfaces by PLL for conjugation of GNPs. ${ }^{44} \mathrm{On}$ GNPs surfaces, biotinylated anti-gp120 polyclonal antibody was immobilized. After capturing of HIV, wavelength shifts in absorbance (extinction) maxima were observed.

As discussed earlier, Au island films were fabricated on the end face of an optical fiber to develop fiber optic-based LSPR sensor for dengue detection. ${ }^{45}$ On the optical fiber end face, a gold thin film of $6 \mathrm{~nm}$ thickness was sputter deposited followed by annealing for 4 minutes at $600^{\circ} \mathrm{C}$. Dengue antiNS1 antibody was immobilized on the surface. The sensor was able to detect NS1 antigen at different concentrations, and the limit of quantification was estimated as $0.074 \mu \mathrm{g} /$ $\mathrm{mL}(1.54 \mathrm{nM})$. Recently, Zhang et $\mathrm{al}^{46}$ demonstrated paperbased immunoassays for the detection of dengue-specific immunoglobulins in salivary fluid. The detection of denguespecific $\operatorname{IgG}$ was shown by the liquid conjugate approach using protein G-conjugated $40 \mathrm{~nm}$ GNPs.
A common biomarker for infectious disease is human radical S-adenosyl methionine domain-containing 2 (RSAD2) gene. Vo-Dinh group ${ }^{48}$ demonstrated SERS-based detection of RSAD2 using molecular sentinel (MS) plasmonic nanoprobes. The MS probe consisted of a DNA strand having a Cy3 Raman label molecule at one end and a silver metal nanoparticle at the other. In the absence of target DNA, the probe DNA sequence formed a hairpin loop maintaining the Raman label in close proximity to the metal nanoparticle, resulting in an intense SERS signal of the Raman label upon laser excitation. The Raman label molecule was physically separated from the metal nanoparticle due to hybridization of a complementary target DNA sequence to the nanoprobe hairpin loop, producing a reduced SERS signal. The same group later immobilized MS on a metal film over nanosphere (MFON) substrate fabricated by depositing gold film over close-packed arrays of polystyrene beads for RSAD2 detection (Figure 4). ${ }^{48}$ The researchers further demonstrated simultaneous detection of multiple host genetic biomarkers interferon alpha-inducible protein 27 and interferon-induced protein 44-like for infectious disease diagnosis using the same SERS platform. ${ }^{49}$

Recently, Pang et al ${ }^{50}$ showed the detection of the RNA genetic marker associated with high pathogenicity influenza (HPAI) virus. As discussed earlier, an MS-modified MFON substrate was prepared. The SERS signal displayed a linear relationship to the target RNA in the range of $0-60 \mathrm{aM}$ and with 2.67 aM LOD.

Similarly, a multispot gold-capped silica nanoparticle array chip ${ }^{51,52}$ was fabricated for AI virus detection. ${ }^{53}$ The gold binding polypeptide (GBP)-fusion protein was used for immobilization of the AI surface antigen on the chip surface

Table 2 Nanoplasmonic biosensors for pathogenic disease diagnosis

\begin{tabular}{|c|c|c|c|c|c|c|}
\hline $\begin{array}{l}\text { Nanostructure } \\
\text { type }\end{array}$ & Probe moieties & Analytes & $\begin{array}{l}\text { Limit of } \\
\text { detection }\end{array}$ & $\begin{array}{l}\text { Substrate } \\
\text { type }\end{array}$ & $\begin{array}{l}\text { Detection } \\
\text { mechanism }\end{array}$ & References \\
\hline$\overline{\text { GNPs }}$ & $\begin{array}{l}\text { Envelope (E) protein of } \\
\text { West Nile Virus (WNV) }\end{array}$ & $\begin{array}{l}\text { Anti-West Nile Virus } \\
(W N V) \text { envelope (E) } \\
\text { immunoglobulin }\end{array}$ & $50 \mathrm{pg} / \mathrm{mL}$ & Colloidal & SERS & Neng et $\mathrm{a}^{43}$ \\
\hline GNPs & Dengue anti-NSI antibody & NSI antigen & $0.074 \mu \mathrm{g} / \mathrm{mL}$ & Fiber optic & LSPR & Camara et $\mathrm{al}^{45}$ \\
\hline $\begin{array}{l}\text { Gold-capped silica } \\
\text { nanoparticle array }\end{array}$ & $\begin{array}{l}\text { Raman label tagged MS } \\
\text { hairpin-DNA probes }\end{array}$ & $\begin{array}{l}\text { RNA marker of } \\
\text { HPAl virus }\end{array}$ & $2.67 \mathrm{aMs}$ & Glass & SERS & Pang et $\mathrm{a}^{50}$ \\
\hline $\begin{array}{l}\text { Gold-capped silica } \\
\text { nanoparticle array }\end{array}$ & Aptamer & Bacteria & $30 \mathrm{cfu}$ & Glass & LSPR & Yoo et a $\mathrm{l}^{54}$ \\
\hline $\begin{array}{l}\text { Au triangle } \\
\text { nanoarray }\end{array}$ & $\begin{array}{l}\text { Detection probe conjugated } \\
\text { with Ag nanorice@MGITC@ } \\
\mathrm{SiO}_{2} \text {, DNA-capture probe }\end{array}$ & HBV DNA & $50 \mathrm{aM}$ & $\begin{array}{l}\text { Silicon } \\
\text { wafer }\end{array}$ & SERS & Li et $\mathrm{a}^{55}$ \\
\hline Au-dots & $\begin{array}{l}\text { HIV-I neutralizing gp I } 20 \\
\text { monoclonal antibody }\end{array}$ & HIV-I & $200 \mathrm{fg} / \mathrm{mL}$ & ITO glass & SPR & Lee et $\mathrm{al}^{57}$ \\
\hline
\end{tabular}

Abbreviations: SPR, surface plasmon resonance; MS, molecular sentinel; gP I 20, glycoprotein I20; GNPs, gold nanoparticles; SERS, surface-enhanced Raman scattering; LSPR, localized surface plasmon resonance; HPAl, high pathogenicity influenza; MGITC, malachite green isothiocyanate; cfu, colony forming unit; HIV, human immunodeficiency virus; HBV, Hepatitis B Virus; ITO, indium tin oxide. 


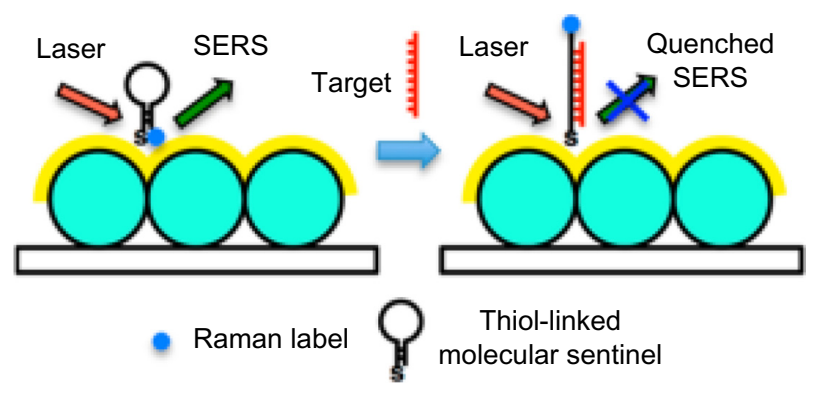

Figure 4 Schematic representation of label-free RSAD2 detection. Notes: Reprinted with permission from Ngo HT, Wang HN, Fales AM, Vo-Dinh T. Label-free DNA biosensor based on SERS molecular sentinel on nanowave chip. Anal Chem. 2013;85(13):6378-6383. ${ }^{48}$ Copyright (C 2013, American Chemical Society. Abbreviations: SERS, surface-enhanced Raman spectroscopy; RSAD2, radical S-adenosyl methionine domain-containing 2.

for anti-AI antibody detection. In recent times, label-free accurate detection of bacteria was demonstrated on a similar sensor surface..$^{54}$ The sensor chip was functionalized with aptamer for multiplex detection of three different bacteria, L. acidophilus, S. typhimurium, and P. aeruginosa. It was able to detect 30 colony forming units (cfu) in an assay comparable to other sensing techniques.

The previously discussed Au triangle nanoarray sensor platform was extended by the same group for hepatitis B virus (HBV) DNA detection (Figure 5). ${ }^{55} \mathrm{Ag}$ nanorice was conjugated with Raman label MGITC followed by $\mathrm{SiO}_{2}$ coating (Ag nanorice@MGITC@SiO ${ }_{2}$ ). The DNA detection probe was immobilized on these sandwich nanoparticles. DNAcapture probe was immobilized on the Au triangle nanoarray. The sandwich nanoparticles were coupled via HBV DNA to the Au triangle nanoarray. The LOD of $50 \mathrm{aM}$ was observed toward HBV DNA with the capability of discriminating a single-base mutant of DNA.

A label-free optofluidic plasmonic nanohole sensor was fabricated using positive resist e-beam lithography and direct deposition of gold layer without lift-off process. ${ }^{56}$ The sensor surface was functionalized with antiviral immunoglobulins for recognition of vesicular stomatitis virus - glycoproteins (GPs) (8G5), Ebola-GP (M-DA01-A5), and Vaccinia-GP (A33L). The detection limit $<10^{5} \mathrm{pfu} / \mathrm{mL}$ was obtained. Recently, Lee et al ${ }^{57}$ fabricated nanopatterns of circular Audots (10-20 nm) on an indium tin oxide (ITO)-coated glass substrate for detection of HIV-1. The detection limit of the HIV-1 particles was estimated to be $200 \mathrm{fg} / \mathrm{mL}$.

Nanoparticle cluster arrays (NCAs) were obtained by combining top-down and bottom-up fabrication techniques. ${ }^{58}$ In the first step of fabrication, e-beam was used to define binding sites for colloidal NPs. The created binding sites surface was made positively charged to enable binding of negatively charged AuNPs. NCAs were evaluated as potential biosensing substrates with two Gram-positive bacteria, Bacillus cereus (B. cereus) and Staphylococcus aureus (S. aureus), and one Gram-negative bacterium, Escherichia coli (E. coli), using the SERS technique.

In parallel to GNP, a GNRs-based biosensor was developed for hepatitis B surface antigen (HbsAg) detection in colloidal solution. ${ }^{59}$ GNRs (with a length of $68 \pm 8 \mathrm{~nm}$ and a width of $30 \pm 5 \mathrm{~nm}$ ) were modified by monoclonal hepatitis B surface antibody (HbsAb) via physical adsorption. Upon incubation with $\mathrm{HbsAg}$, a red shift of the longitudinal band was observed due to the binding events.

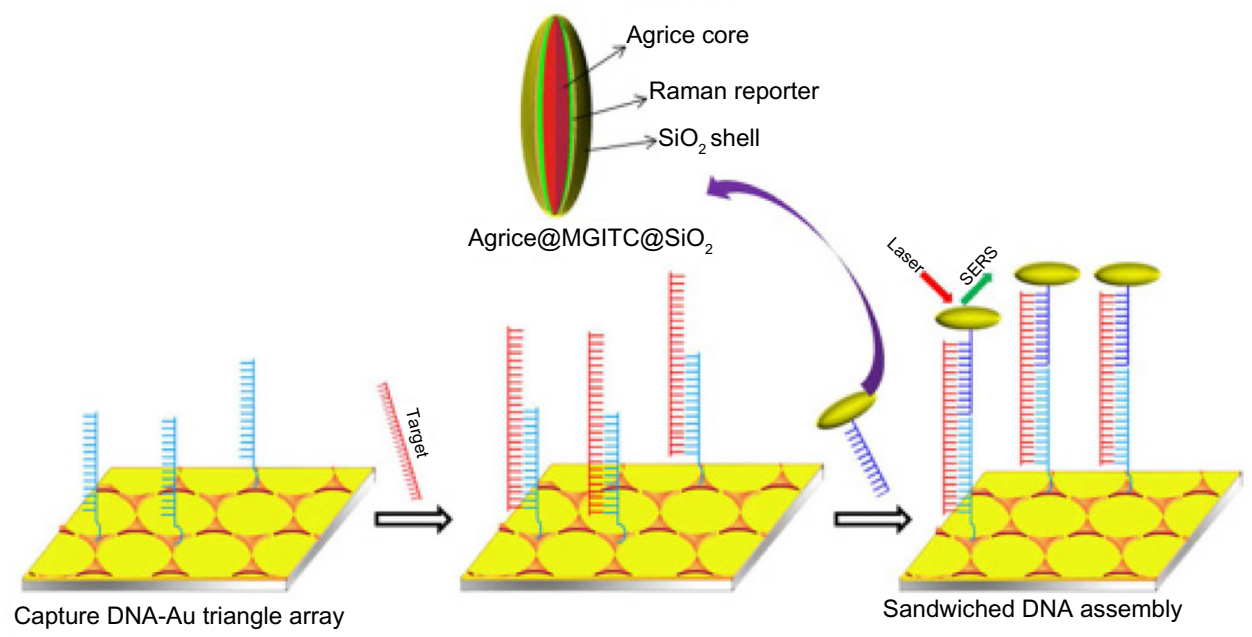

Figure 5 Schematic representation of the SERS sensor for HBV DNA detection.

Notes: Reprinted with permission from Li M, Cushing SK, Liang H, Suri S, Ma D, Wu N. Plasmonic nanorice antenna on triangle nanoarray for surface-enhanced Raman scattering detection of hepatitis B virus DNA. Anal Chem. 2013;85(4):2072-2078. ${ }^{55}$ Copyright @ 2013, American Chemical Society.

Abbreviations: SERS, surface-enhanced Raman spectroscopy; HBV, hepatitis B virus. 
Table 3 Nanoplasmonic biosensors for Alzheimer's disease diagnosis

\begin{tabular}{|c|c|c|c|c|c|c|}
\hline Nanostructure type & Probe moieties & Analytes & $\begin{array}{l}\text { Limit of } \\
\text { detection }\end{array}$ & $\begin{array}{l}\text { Substrate } \\
\text { type }\end{array}$ & $\begin{array}{l}\text { Detection } \\
\text { mechanism }\end{array}$ & References \\
\hline Triangular Ag nanoparticles & Anti-ADDL antibody & ADDL & $10 \mathrm{pM}$ & Mica & LSPR & Haes et $a^{160}$ \\
\hline Silica-gold core-shell & Tau-mAb & Tau protein & $10 \mathrm{pg} / \mathrm{mL}$ & Glass & LSPR & Vestergaard et $\mathrm{a}^{|6|}$ \\
\hline Spherical gold nanoparticles & Tau-mAb & Tau protein & $\mathrm{l} \mathrm{pg} / \mathrm{mL}$ & Colloidal & $\begin{array}{l}\text { Two-photon } \\
\text { Rayleigh scattering }\end{array}$ & Neely et $\mathrm{a}^{62}$ \\
\hline
\end{tabular}

Abbreviations: ADDL, amyloid-derived diffusible ligands; LSPR, localized surface plasmon resonance; tau-mAb, monoclonal anti-tau antibody.

\section{Alzheimer's disease}

Alzheimer's disease (AD) is a progressive neurodegenerative disease that causes dementia in people over age $65 .{ }^{60}$ Early diagnosis of $\mathrm{AD}$ is vital for the current drug treatment as there is no cure for the disease. The different detection techniques for the diagnosis of $A D$ are summarized in Table 3 . The studies showed a central role for amyloid- $\beta(A \beta)$ in the pathogenesis of $A D$. It was found that $A \beta$ is the monomeric subunit of the large insoluble amyloid fibrils of AD plaque and also self-assemble into small soluble oligomers named as amyloid-derived diffusible ligands (ADDLs) ${ }^{60}$ For the detection of ADDLs, Van Duyne group ${ }^{60}$ developed a nanoscale optical biosensor (Figure 6). It consisted of triangular Ag nanoparticles (perpendicular bisectors $=90 \mathrm{~nm}$, height $=25 \mathrm{~nm}$ ) synthesized using the NSL technique. The nanosensor surface was functionalized with, first, anti-ADDL antibody to monitor the interaction between the ADDLs, and, second, anti-ADDL antibodies in a sandwiched assay format. The shift in LSPR wavelength for ADDLs concentration down to $\sim 10 \mathrm{pM}$ displayed this nanosensor as a promising tool for the diagnosis of $\mathrm{AD}$.

The previously discussed multispot gold-capped silica nanoparticle array chip ${ }^{51,52}$ was developed with some

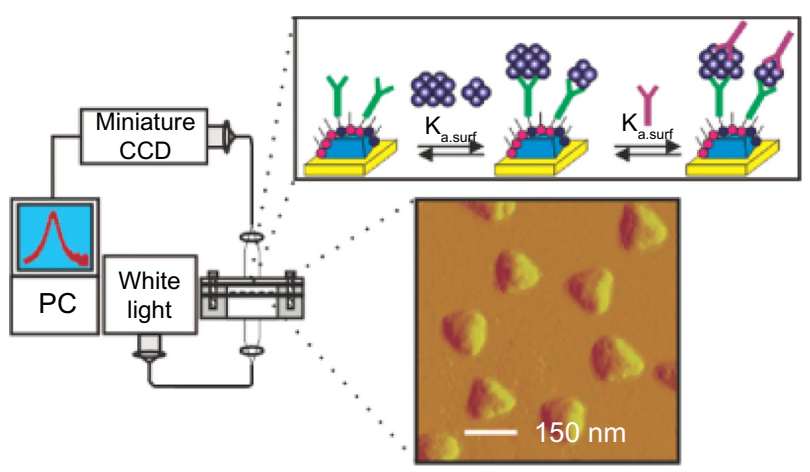

Figure 6 Schematics representing the LSPR biosensor setup for ADDLs detection using a sandwich assay.

Notes: Reprinted with permission from Haes AJ, Chang L, Klein WL, Van Duyne RP. Detection of a biomarker for Alzheimer's disease from synthetic and clinical samples using a nanoscale optical biosensor. J Am Chem Soc. 2005;127(7):2264-2271. ${ }^{60}$ Copyright (C) 2005, American Chemical Society.

Abbreviations: LSPR, localized surface plasmon resonance; ADDLs, amyloidderived diffusible ligands; CCD, charge-coupled device; PC, personal computer. modifications for tau protein (another widely studied biomarker of $\mathrm{AD}$ ) detection. ${ }^{61}$ The chip was functionalized with protein $\mathrm{G}$ for immobilization of a monoclonal anti-tau antibody (tau-mAb). The antibody-immobilized LSPR chip was able to detect $10 \mathrm{pg} / \mathrm{mL}$ tau protein. In another study, Neely et al ${ }^{62}$ detected tau protein by twoPhoton Rayleigh scattering properties of GNP. Spherical GNPs ( $\sim 4 \mathrm{~nm}$ diameter) functionalized with tau-mAb were able to detect Alzheimer's tau protein at the $1 \mathrm{pg} /$ $\mathrm{mL}$ level.

\section{Myocardial infarction}

Worldwide, myocardial infarction (MI) is still a foremost cause of death. Early diagnosis plays a vital role in improving the survival rate. Troponin $\mathrm{T}$ is identified as an unusual myocardial injury marker that forms complexes with Troponin I and Troponin C. ${ }^{63}$ Other preferred biomarkers for MI diagnosis are cardiac troponin I (cTnI) and myoglobin. The LSPR-based sensing mechanism for MI biomarkers detection is demonstrated on entirely different nanostructure platforms, as summarized in Table 4.

A nanoporous AAO layer was employed as a sensing membrane for Troponin $\mathrm{T}$ detection. ${ }^{63}$ The nanoporous substrate, having pores of various depths, was fabricated by a two-step anodizing method. On the sensing membrane, 50 Å thick nickel and $150 \AA \AA$ thick gold layers were deposited for Troponin $\mathrm{T}$ antibody immobilization. The binding of Troponin $T$ reflected as a change in the wavelength of reflection spectrum. The LOD was observed to be $1 \mathrm{ng} / \mathrm{mL}$.

Au nanohole array was fabricated on poly(dimethylsiloxane) (PDMS) by template transfer to detect cTnI. ${ }^{64}$ Anti-cTnI was physically attached on the sensor surface, and the detection limit of the system was observed to be less than $0.4 \mathrm{nM}$. Tang et $a l^{65}$ demonstrated cTnI detection using a GNR bioprobe along with $\mathrm{Fe}_{3} \mathrm{O}_{4}$ magnetic nanoparticles (MNPs) for LSPR enhancement. GNRs and MNPs were functionalized with antibodies (anti-cTnIs) having affinity for different epitopes on the cTnI molecule forming a sandwiched assay (Figure 7). LSPR sensitivity was increased up to 6-fold due 
Table 4 Nanoplasmonic biosensors for myocardial infarction

\begin{tabular}{|c|c|c|c|c|c|c|}
\hline Nanostructure type & Probe moieties & Analytes & $\begin{array}{l}\text { Limit of } \\
\text { detection }\end{array}$ & Substrate type & $\begin{array}{l}\text { Detection } \\
\text { mechanism }\end{array}$ & References \\
\hline AAO layer & Troponin $\mathrm{T}$ antibody & Troponin T & $\mathrm{I} \mathrm{ng} / \mathrm{mL}$ & Aluminum foil & LSPR & Yeom et $\mathrm{al}^{63}$ \\
\hline Nanohole array & Anti-cTnl antibody & cTnl & $0.4 \mathrm{nM}$ & PDMS & LSPR & Jia et $\left.a\right|^{64}$ \\
\hline GNR + MNPs & Anti-cTnl antibody & cTnl & 30 pM & Colloidal & LSPR & Tang et $\mathrm{a}^{65}$ \\
\hline
\end{tabular}

Abbreviations: AAO, anodized aluminum oxide; LSPR, localized surface plasmon resonance; cTnl, cardiac troponin I; PDMS, poly(dimethylsiloxane); GNR, gold nanorods; MNPs, magnetic nanoparticles.

to MNP and GNR combination. The LOD for plasma cTnI assay was $30 \mathrm{pM}$ with a signal-to-noise ratio $>3$. Later, the same author established a multibiomarker detection strategy to improve the reliability of cardiovascular diagnosis at the early stages. ${ }^{66}$ A multiplexed GNR sensor was developed by combining nanorods of aspect ratios 2.1 and 4.2 having distinct LSPR at 640 and $830 \mathrm{~nm}$. GNRs were functionalized with antimyoglobin or anti-cTnI antibody. A significant red shift at $640 \mathrm{~nm}$ was related to myoglobin, while plasmon shift at $830 \mathrm{~nm}$ was related to cTnI binding.

\section{Other plasmonic platforms for disease diagnosis}

In the preceding sections, some of the sensors used for some specific diseases have been discussed. Some interesting nanoplasmonic structures have been developed, which might as well be used for the purposes of detecting markers of various diseases or pathogens. Some of these are discussed in this section, with a view to facilitating their adoption for disease detection by readers of this article.

Quite a few sensing structures have been developed and validated using biotin-streptavidin binding. In one such study,

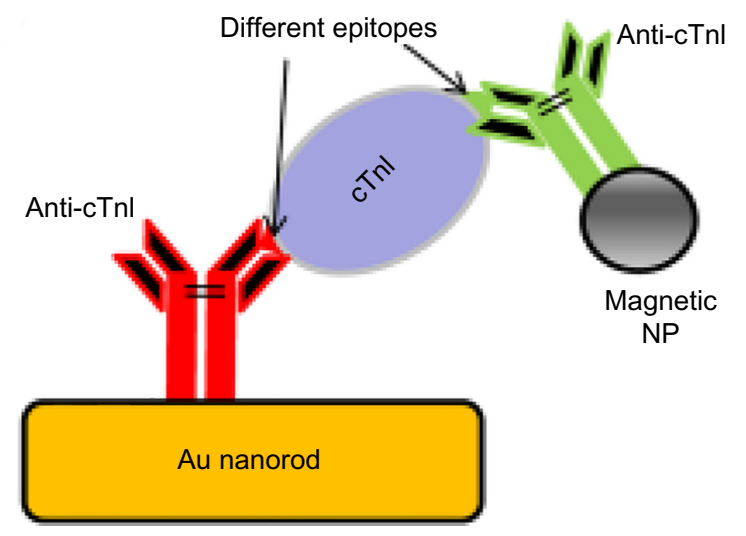

Figure 7 Scheme of MNP-mediated LSPR assay on gold nanorod.

Notes: Reprinted with permission from Tang L, Casas J, Venkataramasubramani M. Magnetic nanoparticle mediated enhancement of localized surface plasmon resonance for ultrasensitive bioanalytical assay in human blood plasma. Anal Chem. 2013;85(3):1431-1439. ${ }^{65}$ Copyright @ 2013, American Chemical Society.

Abbreviations: MNP, magnetic nanoparticles; LSPR, localized surface plasmon resonance; cTnl, cardiac troponin I. a silver-nanoparticles-on-plastic sensor (SNOPS) was fabricated by chemically modifying the surface of polyethylene terephthalate for immobilization of Ag NPs. ${ }^{67}$ Biotin was immobilized on the SNOPS strips for streptavidin antigen (SA) detection. The sensor exhibited a linear response in the SA concentration in the range 9.5-189.4 nM, and LOD was estimated at $3.5 \mathrm{nM}(190 \mathrm{ng} / \mathrm{mL})$. A similar study was done using hollow gold nanoparticles (HGNs) synthesized on the surface ITO glass ${ }^{68}$ The sensor displayed a linear response in the SA concentration range from $3 \times 10^{-10}$ to $1 \times 10^{-7} \mathrm{M}$. Another interesting structure was developed by Bi et al, ${ }^{69}$ who fabricated silver-modified gold nanoplate arrays by chemical synthesis. SERS intensity was observed with streptavidin/ biotin assemblies on the surface of these bimetallic nanoplate arrays, and LOD of biotin was obtained down to $1 \mathrm{nM}$. A uniform array of gold nanodisks $(190 \mathrm{~nm}$ in diameter and $20 \mathrm{~nm}$ tall) was fabricated using Hole-mask colloidal lithography. ${ }^{70}$ A LSPR peak shift denoted immunoreaction on the surface of this sensor. In view of the uniformity of the array, it may be possible to use this system in a multiplexed format.

Another structure of interest, namely, an array of gold nanodisks supported by dielectric pillars, was produced by an isotropic chemical etch of a nanopatterned substrate. ${ }^{71}$ This has been used to monitor DNA hybridization, wherein a short single-stranded DNA sequence (32-mer) from the iap gene of the bacteria Listeria innocua was utilized. Hybridization experiments have also been carried out on gold nanorings, fabricated using the NSL technique. ${ }^{72}$ Polystyrene beads $(100 \mathrm{~nm})$ were used as templates on which $30 \mathrm{~nm}$ gold film was deposited. This followed by 60 seconds ion milling produced nanorings of average inner and outer diameters of 100 and $130 \mathrm{~nm}$, respectively, with an interstructure spacing of $200 \mathrm{~nm}$. After ssDNA probe immobilization, the LSPR peak position red-shifted by $8.2 \mathrm{~nm}$. Further $3.1 \mathrm{~nm}$ redshift was seen after the hybridization with the complementary target DNA. In another recent study, gold nanoring arrays were fabricated using a combination of colloidal lithography and lithographically patterned nanoscale electrodeposition. ${ }^{73}$ A hybridization of DNA-functionalized GNPs with complementary DNA on the nanorings exhibited a LSPR shift, 


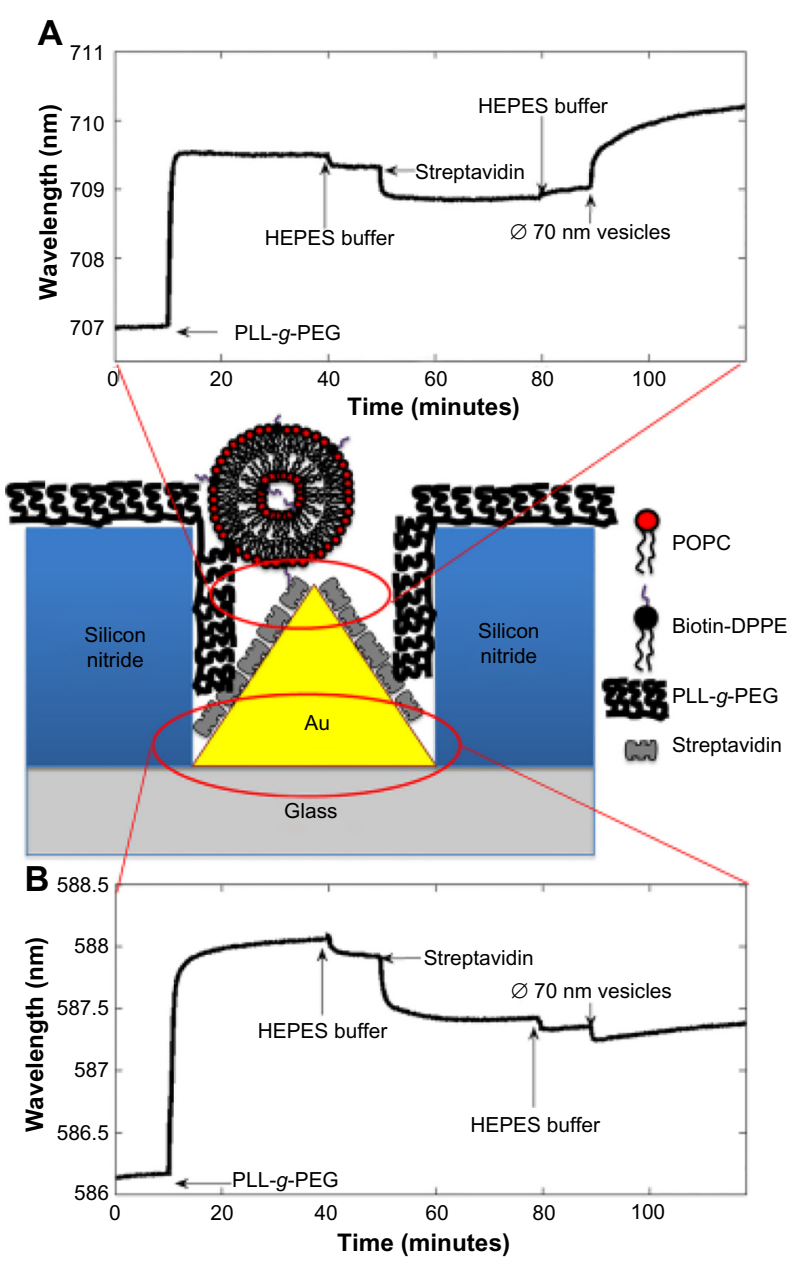

Figure 8 Schematic representation indicating sensor responses at the base and tip of the nanomenhirs for monitoring the molecular assembly.

Notes: On addition of $\varnothing 70 \mathrm{~nm}$ biotinylated vesicles, strong redshift in signal is seen for the plasmon excitation corresponding to the apex of the nanomenhirs $(\mathbf{A})$, whereas a weak redshift for the plasmon excitation corresponding to the base of the nanomenhirs is seen (B). Reprinted with permission from Kumar K, Dahlin AB, Sannomiya T, Kaufmann S, Isa L, Reimhult E. Embedded plasmonic nanomenhirs as location-specific biosensors. Nano Lett. 20|3;|3(I2):6I22-6129. ${ }^{74}$ Copyright (C) 20I3, American Chemical Society.

Abbreviations: PLL, poly-L-lysine; PEG, polyethylene glycol; HEPES, 4-(2-hydroxyethyl) piperazine-I-ethane sulfonic acid; POPC, I-palmitoyl-2-oleoyl-sn-glycero-3-phosphocholine; DPPE, I,2-Dipalmitoyl-sn-glycero-3-phosphoethanolamine.

demonstrating the ability of this system to detect various bioaffinity interactions.

A very interesting structure has been described by Kumar et $\mathrm{al}^{74}$ (Figure 8). This comprised uniaxially aligned nanocones (nanomenhirs) inside silicon nitride nanocavities. As a proof of concept, detection of binding of liposomes to one part of the sensor structure, and small protein binding to another part of the structure was demonstrated. As can be seen, there are distinctly different responses (in terms of initial wavelength) from the tip and the base. Further, in each of these spatial locations, the response to small molecules was a blue shift, and liposomes led to a red shift.

\section{Conclusion}

Plasmonics, particularly LSPR and SERS, is a nanoscale phenomenon, by definition. Although both of these were known much before the nanotechnology boom, it is only now, with concomitant advances in both bottom-up and top-down fabrication technologies, that the real potential of nanoplasmonics is being unearthed. Work in this area is proceeding at a phenomenal pace, with a large number of groups dedicated to creating novel nanostructures that in isolation, arrays, or interacting couplets/triplets exploit properties of plasmons for sensing analytes at hitherto unheard concentrations. Groups have also worked on various substrates, some of which are flat, and others with nanostructures in the substrate material itself. Unfortunately, we could highlight only a small fraction (less than 75 or more than 5,000 ) of the excellent reports that have been published in the last decade.

It is obvious that a large number of analytes of interest will be in the medical and biological domains, particularly in disease diagnostics. With the ever-increasing cost of health care, early detection and routine population screening of diseases is becoming increasingly important. This has resulted in a large unmet need of inexpensive sensors that will help reduce the costs of health care to the governments and insurers. Although the cost of the noble metals is unlikely to decrease, by innovative design of nanostructures that can be fabricated using bottom-up techniques (as opposed to topdown techniques like EBL), it might be possible to reduce the cost of such sensors. It might also be possible to reduce the cost by adopting inexpensive substrates like plastics, in the form of sheets or even plastic optical fibers. One example has been given in this review. There are many others who are working on similar substrates. Further reduction in cost might be achieved by designs that allow multiplexed sensing (as in sensor arrays). It is conceivable that sensors such as these will have a large impact on the health care scenario in the underserved segment of the global population.

The use of LSPR for the detection of various analytes is not a new area of research. There are many reviews that discuss refractometric nanoplasmonic biosensors, SERS-based biosensors, plasmon-enhanced fluorescence biosensors, etc. In this review, we have discussed various nanoplasmonic biosensors employed for disease diagnosis. It is indeed true that, similar to other areas of research, all the different kinds of nanostructures do not come up to the level of disease diagnosis in commercial terms. Some of them can detect only model disease biomarkers well enough in the laboratories, but are not particularly suited toward commercial deployment. 
The main challenges in commercialization of biosensors are shelf life, repeatability, and sensitivity. Although the latter may be achieved, the former factors might not easily translate from the lab to the market. Colloidal nanostructures face inherent problems of stability in solution, settling down with the slightest change in conditions. This may give rise to lack of repeatability and sensitivity. Hence, most of the research now is in confining nanostructures on substrates. This is accomplished either by 1) dispersing nanostructures made in solutions onto subtrates, and attaching them chemically or by entrapment; or 2) by growing nanostructures on substrates directly. Besides the issues of stability of the nanostructures, biofunctionalization is another issue to consider. Although many chemical methods are available for this purpose, the biological recognition of molecules frequently requires a controlled environment (in terms of temperature, humidity, etc) for long-term stability. This is a stumbling block in terms of commercialization.

In spite of various obstacles, some nanoparticle-based diagnostic kits are available commercially. One of the first is the home pregnancy device First Response ${ }^{\circledR}$ offered by Church and Dwight Co, Inc. (Ewing, NJ, USA). For disease diagnosis, laboratory equipment incorporating nanoparticles for sensing has been commercialized by some companies. Nanosphere, Inc. (Northbrook, IL, USA) has come up with the Verigene ${ }^{\circledR}$ System for detection of nucleic acids and high-sensitivity proteins on the same platform using GNP probes. Pharma Diagnostics NV (Zellik, Belgium) have established a label-free LSPR technology called the SoPRano ${ }^{\mathrm{TM}}$ platform for research and pharmaceutical discovery. In this case, interaction of target protein molecules attached to the surface of the GNRs with a ligand is measured on a standard absorbance plate reader. Merck’s Singlepath ${ }^{\circledR}$ E.coli 0157 (Merck Millipore, Billerica, MA, USA) is a gold-labeled immunosorbent assay for the qualitative detection of E. coli $\mathrm{O} 157$ in food. Thus, some commercial products are already available for medical and biological use, and others are also expected to be commercialized soon, given the large number of nanotechnology start-up companies around the world, many of them being incubated in educational institutes. There is no doubt that this domain of science will have a significant impact on health care delivery and personalized medicine in the years to come.

\section{Disclosure}

The authors report no conflicts of interest in this work.

\section{References}

1. Wei H, Xu H. Plasmonics in composite nanostructures. Mater Today. 2014;17(8):372-380.
2. Larguinho M, Baptista PV. Gold and silver nanoparticles for clinical diagnostics - from genomics to proteomics. J Proteomics. 2012;75(10): 2811-2823.

3. Mayer KM, Hafner JH. Localized surface plasmon resonance sensors. Chem Rev. 2011;111(6):3828-3857.

4. Satija J, Bharadwaj R, Sai VVR, Mukherji S. Emerging use of nanostructure films containing capped gold nanoparticles in biosensors. Nanotechnol Sci Appl. 2010;3(1):171-188.

5. Anker JN, Hall WP, Lyandres O, Shah NC, Zhao J, Van Duyne RP. Biosensing with plasmonic nanosensors. Nat Mater. 2008;7(6): 442-453.

6. Bauch M, Toma K, Toma M, Zhang Q, Dostalek J. Plasmon-enhanced fluorescence biosensors: a review. Plasmonics. 2014;9:781-799.

7. Luo SC, Sivashanmugan K, Liao JD, Yao CK, Peng HC. Nanofabricated SERS-active substrates for single-molecule to virus detection in vitro: a review. Biosens Bioelectron. 2014;61:232-240.

8. Sharma B, Fernanda Cardinal M, Kleinman SL, et al. High-performance SERS substrates: advances and challenges. MRS Bull. 2013;38(8): 615-624.

9. Pilo-Pais M, Watson A, Demers S, Labean TH, Finkelstein G. Surfaceenhanced Raman scattering plasmonic enhancement using DNA origami-based complex metallic nanostructures. Nano Lett. 2014;14(4): 2099-2104.

10. Grzelczak M, Liz-Marzán LM. Colloidal nanoplasmonics: from building blocks to sensing devices. Langmuir. 2013;29(15):4652-4663.

11. Santos A, Kumeria T, Losic D. Optically optimized photoluminescent and interferometric biosensors based on nanoporous anodic alumina: a comparison. Anal Chem. 2013;85(16):7904-7911.

12. Estevez MC, Otte MA, Sepulveda B, Lechuga LM. Trends and challenges of refractometric nanoplasmonic biosensors: a review. Anal Chim Acta. 2014;806:55-73.

13. Trasobares J, Vaurette F, François M, et al. High speed e-beam lithography for gold nanoarray fabrication and use in nanotechnology. Beilstein J Nanotechnol. 2014;5:1918-1925.

14. Coluccio ML, Gentile F, Francardi M, et al. Electroless deposition and nanolithography can control the formation of materials at the nano-scale for plasmonic applications. Sensors. 2014;14(4):6056-6083.

15. Staude I, Decker M, Ventura MJ, et al. Hybrid high-resolution threedimensional nanofabrication for metamaterials and nanoplasmonics. Adv Mater. 2013;25(9):1260-1264.

16. Xia D, Ku Z, Lee SC, Brueck SRJ. Nanostructures and functional materials fabricated by interferometric lithography. Adv Mater. 2011;23(2):147-179.

17. Giner-Casares JJ, Liz-Marzán LM. Plasmonic nanoparticles in 2D for biological applications: toward active multipurpose platforms. Nano Today. 2014;9(3):365-377.

18. Acikgoz C, Hempenius MA, Huskens J, Vancso GJ. Polymers in conventional and alternative lithography for the fabrication of nanostructures. Eur Polym J. 2011;47(11):2033-2052.

19. Biswas A, Bayer IS, Biris AS, Wang T, Dervishi E, Faupel F. Advances in top-down and bottom-up surface nanofabrication: techniques, applications and future prospects. Adv Colloid Interface Sci. 2012;170(1-2):2-27.

20. Perfézou M, Turner A, Merkoçi A. Cancer detection using nanoparticlebased sensors. Chem Soc Rev. 2012;41(7):2606-2622.

21. Cho H, Yeh EC, Sinha R, Laurence TA, Bearinger JP, Lee LP. Singlestep nanoplasmonic VEGF 165 aptasensor for early cancer diagnosis. ACS Nano. 2012;6(9):7607-7614.

22. Cao C, Li X, Lee J, Sim SJ. Homogenous growth of gold nanocrystals for quantification of PSA protein biomarker. Biosens Bioelectron. 2009;24(5):1292-1297.

23. Hwang WS, Truong PL, Sim SJ. Size-dependent plasmonic responses of single gold nanoparticles for analysis of biorecognition. Anal Biochem. 2012;421(1):213-218.

24. Wang A, Ruan W, Song W, et al. Detection of the potential tumor marker of AFP using surface-enhanced Raman scattering-based immunoassay. J Raman Spectrosc. 2013;44(12):1649-1653. 
25. Chang YF, Chen RC, Lee YJ, et al. Localized surface plasmon coupled fluorescence fiber-optic biosensor for alpha-fetoprotein detection in human serum. Biosens Bioelectron. 2009;24(6):1610-1614.

26. Jeong H-H, Erdene N, Park J, Jeong D, Lee H-Y, Lee S. Real-time labelfree immunoassay of interferon-gamma and prostate-specific antigen using a fiber-optic localized surface plasmon resonance sensor. Biosens Bioelectron. 2013;39(1):346-351.

27. Li K, Liu G, Wu Y, Hao P, Zhou W, Zhang Z. Gold nanoparticle amplified optical microfiber evanescent wave absorption biosensor for cancer biomarker detection in serum. Talanta. 2014;120:419-424.

28. Tabakman SM, Lau L, Robinson JT, et al. Plasmonic substrates for multiplexed protein microarrays with femtomolar sensitivity and broad dynamic range. Nat Commun. 2011;2:466.

29. Geng Z, Kan Q, Yuan J, Chen H. A route to low-cost nanoplasmonic biosensor integrated with optofluidic-portable platform. Sensors Actuators B Chem. 2014;195:682-691.

30. Li M, Cushing SK, Zhang J, et al. Three-dimensional hierarchical plasmonic nano-architecture enhanced surface-enhanced Raman scattering immunosensor for cancer biomarker detection in blood plasma. ACS Nano. 2013;7(6):4967-4976.

31. Lee SW, Lee KS, Ahn J, Lee JJ, Kim MG, Shin YB. Highly sensitive biosensing using arrays of plasmonic Au nanodisks realized by nanoimprint lithography. ACS Nano. 2011;5(2):897-904.

32. Sanders M, Lin Y, Wei J, Bono T, Lindquist RG. An enhanced LSPR fiber-optic nanoprobe for ultrasensitive detection of protein biomarkers. Biosens Bioelectron. 2014;61:95-101.

33. Truong PL, Kim BW, Sim SJ. Rational aspect ratio and suitable antibody coverage of gold nanorod for ultra-sensitive detection of a cancer biomarker. Lab Chip. 2012;12(6):1102-1109.

34. Park H, Lee S, Chen L, et al. SERS imaging of HER2-overexpressed MCF7 cells using antibody-conjugated gold nanorods. Phys Chem Chem Phys. 2009;11(34):7444-7449.

35. Xu X, Ying Y, Li Y. One-step and label-free detection of alphafetoprotein based on aggregation of gold nanorods. Sensors Actuators B Chem. 2012;175:194-200.

36. Tian L, Morrissey JJ, Kattumenu R, Gandra N, Kharasch ED, Singamaneni S. Bioplasmonic paper as a platform for detection of kidney cancer biomarkers. Anal Chem. 2012;84(22):9928-9934.

37. Nima ZA, Mahmood M, XuY, et al. Circulating tumor cell identification by functionalized silver-gold nanorods with multicolor, super-enhanced SERS and photothermal resonances. Sci Rep. 2014;4:4752.

38. Wu L, Wang Z, Zong S, et al. Simultaneous evaluation of p53 and p21 expression level for early cancer diagnosis using SERS technique. Analyst. 2013;138(12):3450-3456

39. Dodson SL, Cao C, Zaribafzadeh H, Li S, Xiong Q. Engineering plasmonic nanorod arrays for colon cancer marker detection. Biosens Bioelectron. 2015;63:472-477.

40. Shen Y, Zhou J, Liu T, et al. Plasmonic gold mushroom arrays with refractive index sensing figures of merit approaching the theoretical limit. Nat Commun. 2013;4:2381.

41. Yuan J, Duan R, Yang H, Luo X, Xi M. Detection of serum human epididymis secretory protein 4 in patients with ovarian cancer using a label-free biosensor based on localized surface plasmon resonance. Int J Nanomedicine. 2012;7:2921-2928.

42. Duan RQ, Yuan JL, Yang H, Luo XG, Xi MR. Detection of p53 gene mutation by using a novel biosensor based on localized surface plasmon resonance. Neoplasma. 2012;59(3):348-353.

43. Neng J, Harpster MH, Zhang H, Mecham JO, Wilson WC, Johnson PA. A versatile SERS-based immunoassay for immunoglobulin detection using antigen-coated gold nanoparticles and malachite green-conjugated protein A/G. Biosens Bioelectron. 2010;26(3): 1009-1015.

44. Inci $\mathrm{F}$, Tokel $\mathrm{O}$, Wang $\mathrm{S}$, et al. Nanoplasmonic quantitative detection of intact viruses from unprocessed whole blood. ACS Nano. 2013; 7(6):4733-4745.

45. Camara AR, Gouvêa PM, Dias AC, et al. Dengue immunoassay with an LSPR fiber optic sensor. Opt. Express. 2013;21(22):27023-27031.
46. Zhang Y, Bai J, Ying JY. A stacking flow immunoassay for the detection of dengue-specific immunoglobulins in salivary fluid. Lab Chip. 2015;15:1465-1471.

47. Wang HN, Fales AM, Zaas AK, et al. Surface-enhanced Raman scattering molecular sentinel nanoprobes for viral infection diagnostics. Anal Chim Acta. 2013;786:153-158.

48. Ngo HT, Wang HN, Fales AM, Vo-Dinh T. Label-free DNA biosensor based on SERS molecular sentinel on nanowave chip. Anal Chem. 2013;85(13):6378-6383.

49. Ngo HT, Wang HN, Burke T, Ginsburg GS, Vo-Dinh T. Multiplex detection of disease biomarkers using SERS molecular sentinel-on-chip multiplex platforms in diagnostics and bioanalytics. Anal Bioanal Chem. 2014;406(14):3335-3344.

50. Pang Y, Wang J, Xiao R, Wang S. SERS molecular sentinel for the RNA genetic marker of PB1-F2 protein in highly pathogenic avian influenza (HPAI) virus. Biosens Bioelectron. 2014;61:460-465.

51. Endo T, Yamamura S, Nagatani N, Morita Y, Takamura Y, Tamiya E. Localized surface plasmon resonance based optical biosensor using surface modified nanoparticle layer for label-free monitoring of antigenantibody reaction. Sci Technol Adv Mater. 2005;6:491-500.

52. Endo T, Kerman K, Nagatani N, et al. Multiple label-free detection of antigen-antibody reaction using localized surface plasmon resonancebased core-shell structured nanoparticle layer nanochip. Anal Chem. 2006;78(18):6465-6475.

53. Park TJ, Lee SJ, Kim DK, Heo NS, Park JY, Lee SY. Development of label-free optical diagnosis for sensitive detection of influenza virus with genetically engineered fusion protein. Talanta. 2012;89:246-252.

54. Yoo SM, Kim D, Lee SY. Aptamer-functionalized localized surface plasmon resonance sensor for the multiplexed detection of different bacterial species. Talanta. 2015;132:112-117.

55. Li M, Cushing SK, Liang H, Suri S, Ma D, Wu N. Plasmonic nanorice antenna on triangle nanoarray for surface-enhanced Raman scattering detection of hepatitis B virus DNA. Anal Chem. 2013;85(4): 2072-2078.

56. Yanik AA, Huang M, Kamohara O, et al. An optofluidic nanoplasmonic biosensor for direct detection of live viruses from biological media. Nano Lett. 2010;10(12):4962-4969.

57. Lee J, Kim B, Oh B, Choi J. Highly sensitive localized surface plasmon resonance immunosensor for label-free detection of HIV-1. Nanomedicine. 2013;9(7):1018-1026.

58. Yan B, Boriskina SV, Reinhard BM. Design and implementation of noble metal nanoparticle cluster arrays for plasmon enhanced biosensing. J Phys Chem C. 2011;115(50):24437-24453.

59. Wang X, Li Y, Wang H, et al. Gold nanorod-based localized surface plasmon resonance biosensor for sensitive detection of hepatitis B virus in buffer, blood serum and plasma. Biosens Bioelectron. 2010;26(2): 404-410.

60. Haes AJ, Chang L, Klein WL, Van Duyne RP. Detection of a biomarker for Alzheimer's disease from synthetic and clinical samples using a nanoscale optical biosensor. J Am Chem Soc. 2005;127(7):2264-2271.

61. Vestergaard M, Kerman K, Kim DK, Hiep HM, Tamiya E. Detection of Alzheimer's tau protein using localised surface plasmon resonancebased immunochip. Talanta. 2008;74(4):1038-1042.

62. Neely A, Perry C, Varisli B, et al. Ultrasensitive and highly selective detection of Alzheimer's disease biomarker using two-photon rayleigh scattering properties of gold nanoparticle. ACS Nano. 2009;3(9):2834-2840.

63. Yeom $\mathrm{SH}$, Kang $\mathrm{BH}$, Kim KJ, et al. Nanoporous aluminum anodic oxide-based optical biosensor for real-time detection of Troponin T. Proc IEEE Sensors. 2011:288-291.

64. Jia P, Jiang H, Sabarinathan J, Yang J. Plasmonic nanohole array sensors fabricated by template transfer with improved optical performance. Nanotechnology. 2013;24(19):195501.

65. Tang L, Casas J, Venkataramasubramani M. Magnetic nanoparticle mediated enhancement of localized surface plasmon resonance for ultrasensitive bioanalytical assay in human blood plasma. Anal Chem. 2013;85(3):1431-1439. 
66. Tang L, Casas J. Quantification of cardiac biomarkers using label-free and multiplexed gold nanorod bioprobes for myocardial infarction diagnosis. Biosens Bioelectron. 2014;61:70-75.

67. Fan M, Thompson M, Andrade ML, Brolo AG. Silver nanoparticles on a plastic platform for localized surface plasmon resonance biosensing. Anal Chem. 2010;82(15):6350-6352.

68. Hu T, Lin Y, Yan J, Di J. Synthesis of hollow gold nanoparticles on the surface of indium tin oxide glass and their application for plasmonic biosensor. Spectrochim Acta A Mol Biomol Spectrosc. 2013;110:72-77.

69. Bi L, Dong J, Xie W, et al. Bimetallic gold-silver nanoplate array as a highly active SERS substrate for detection of streptavidin/biotin assemblies. Anal Chim Acta. 2013;805:95-100.

70. Ruemmele JA, Hall WP, Ruvuna LK, Van Duyne RP. A localized surface plasmon resonance imaging instrument for multiplexed biosensing. Anal Chem. 2013;85(9):4560-4566.
71. Otte MA, Est M, Carrascosa LG, Gonz AB, Lechuga LM. Improved biosensing capability with novel suspended nanodisks. JPhys Chem C. 2011;115:5344-5351.

72. Huang C, Ye J, Wang S, Stakenborg T, Lagae L. Gold nanoring as a sensitive plasmonic biosensor for on-chip DNA detection. Appl Phys Lett. 2012;100(17):17-21.

73. Toma M, Cho K, Wood JB, Corn RM. Gold nanoring arrays for near infrared plasmonic biosensing. Plasmonics. 2013;9(4):765-772.

74. Kumar K, Dahlin AB, Sannomiya T, Kaufmann S, Isa L, Reimhult E. Embedded plasmonic nanomenhirs as location-specific biosensors. Nano Lett. 2013;13(12):6122-6129.

\section{Publish your work in this journal}

Nanobiosensors in Disease Diagnosis is an international, peer-reviewed, open access journal publishing original research, reports, reviews and commentaries including but not confined to: Diagnosis of diseases including cancer, cardiovascular, infectious diseases; Molecular modeling in diagnosis; Enzyme and membrane technologies; and quantum dot fluorescence technologies for monitoring toxins and pathogens. The manuscript management system is completely online and includes a very quick and fair peer-review system, which is all easy to use. Visit http://www.dovepress.com/testimonials.php to read real quotes from published authors.

Submit your manuscript here: http://www.dovepress.com/nanobiosensors-in-disease-diagnosis-journal 